\title{
Thermodynamic Characterization of Adriamycin Binding to DNA: Dependence of Heat of Interaction on GC Composition of DNA
}

\author{
Kazuo Kan@H, Yoshihiro BABA, and Akihiro KagEmoto \\ Laboratory of Chemistry, Department of General Education, \\ Osaka Institute of Technology, \\ Omiya, Asahi-ku, Osaka 535, Japan
}

(Received June 10, 1988)

\begin{abstract}
The interactions between adriamycin (AD) and DNA of various GC content were studied by calorimetry and UV/Vis spectrophotometry. From the results, the thermodynamic parameters accompanying the intercalations were estimated by taking into account the dissociation of the AD dimer to monomer. The stability of the intercalation complex is due to enthalpic and the entropic contributions. The enthalpy change accompanying the intercalations is more exothermic for GC-rich DNA than for AT-rich DNA although the free energy change is independent of GC content of DNA, indicating that the interaction energy of base pair with AD is larger for GC than AT base pairs.

KEY WORDS DNA / Adriamycin / Heat of Mixing / UV/Vis Spectrophotometry / Thermodynamic Parameters / GC Composition of DNA /
\end{abstract}

One of the most interesting areas in biological research is the interactions betwen DNA and small molecules. Specifically, the correlation between the intercalations and inhibition of the transcription or replication of DNA is of importance for understanding gene expression. Common intercalators are characterized by heterocyclic aromatic chromophores and include mutagenic aminoacridine dyes $^{1}$ and many drugs as antitumor agents. ${ }^{2}$

Interactions between DNA and intercalators seem due to insertion of planar aromatic molecules between base pairs of DNA, as judged from the results of sedimentation, ${ }^{3,4} \mathrm{X}$ ray diffraction, ${ }^{5,6}$ viscosity, ${ }^{7}$ and the crystal structure of intercalation complexes. ${ }^{8,9}$

It was previously reported that interactions between the polynucleotide duplex such as $\operatorname{poly}(\mathrm{A}) \cdot \operatorname{poly}(\mathrm{U})$ duplex or $\operatorname{poly}(\mathrm{I}) \cdot \operatorname{poly}(\mathrm{C})$ duplex and mutagenic acridine dye (proflavine and 9-aminoacridine) ${ }^{10,11}$ occur throughout intercalation. However, interactions between the polynucleotide duplex and adriamycin ${ }^{12}$ involve outside, nonintercalation binding. Daunomycin, which has a similar chemical structure to adriamycin, intercalates into DNA $^{13-15}$ and exhibits GC specificity when binding to oligonucleotides as determined from X-ray diffraction studies. ${ }^{16}$ From these experimental results, the intercalation of adriamycin into double stranded helical DNA seems due to the GC base pair and/or to the conformation of the double stranded helical structure since the structure of DNA is Bform $^{17}$ and that of $\operatorname{poly}(\mathrm{A}) \cdot \operatorname{poly}(\mathrm{U})$ duplex and $\operatorname{poly}(\mathrm{I}) \cdot \operatorname{poly}(\mathrm{C})$ duplex is $\mathrm{A}$-form. ${ }^{18}$

In this paper, to obtain thermodynamic information regarding base specificity of interactions between DNA and adriamycin in aqueous solution, we elucidated the thermodynamic parameters of the interaction for adriamycin binding to DNA by measuring the heat of mixing and UV/Vis spectrum, and also explored the effect of GC base composition of 
DNA on binding of adriamycin.

\section{EXPERIMENTAL}

The DNA samples were Clostridum perfringens DNA (GC; 26.5\%, DNA(I)), Eschrichia coli DNA (GC; 50.0\%, DNA(II)) and Micrococcus lydodeikticus DNA (GC; $72.0 \%$, DNA(III)), which were purchased from Sigma Chemical Co., U.S.A. Adriamycin hydrochloride (AD) was also purchased from Sigma. All measurements were made in 0.1 mol $\mathrm{dm}^{-3}$ Tris- $\mathrm{HCl}$ buffer solution at $\mathrm{pH}$ 7.60 .

The calorimeter employed was identical to the LKB batch type microcalorimeter and placed in an air bath kept at $298.15 \pm 0.005 \mathrm{~K}$ as described previously. ${ }^{19}$ For calorimetric measurements, a DNA solution of a known concentration (about $5.0 \times 10^{-4} \mathrm{~mol} \mathrm{dm}^{-3}$ in nucleotide phosphorus) and an $\mathrm{AD}$ solution at various concentrations were mixed. In the calorimetric measurements, the heat of dilution of $\mathrm{AD}$ solution was compensated by preparing an AD solution of same concentration in both the sample and reference cells in the calorimeter. The heat of dilution of DNA was negligibly small. The DNA concentration was determined by the phosphorus analysis method. ${ }^{20}$

The absorption spectra of the mixtures of DNA and AD solutions were measured at room temperature with a Hitachi $220 \mathrm{~A} \mathrm{UV} /$ Vis spectrophotometer. In this case, an AD solution of a known concentration containing various amounts of DNA was employed.

\section{RESULTS AND DISCUSSION}

\section{Absorption Spectra of DNA-AD System}

The typical adsorption spectra obtained for AD solutions containing various amounts of DNA(III) are shown in Figure 1. As seen in Figure 1, the wavelength of the maximum absorption for the DNA(III)-AD system shifts to red as the concentration of DNA(III) in-

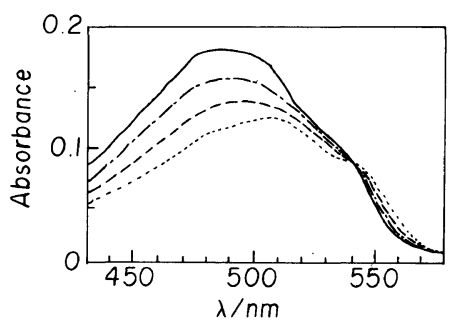

Figure 1. Absorption spectra of adriamycin solution $\left(2.0 \times 10^{-5} \mathrm{~mol} \mathrm{dm}^{-3}\right)$ containing various amounts of DNA (III) (GC content $72 \%$ ) in $0.1 \mathrm{~mol} \mathrm{dm}^{-3}$ Tris- $\mathrm{HCl}$ buffer solution at $\mathrm{pH}$ 7.60. DNA concentration: - , zero; $\quad---, \quad 6.0 \times 10^{-5} ; \quad----, \quad 1.0 \times 10^{-4}$; ----, $2.6 \times 10^{-4} \mathrm{~mol} \mathrm{dm}^{-3}$ in phosphorus unit.

creases, and a well-defined isosbestic point is located at about $540 \mathrm{~nm}$. This red shift and isosbestic point are comparable with the results for DNA-aminoacridine dye ${ }^{21,22}$ and polynucleotide duplex-aminoacridine systems ${ }^{10,11}$ which show interactions based on intercalation, suggesting that the interactions between DNA(III) and AD are due to intercalations similar to those between DNA and aminoacridine dye. ${ }^{23}$

The absorption spectra for DNA(I) and/or DNA(II) and AD systems are similar to those for DNA(III) and AD system as mentioned above.

The percentage of bound AD to DNA was calculated according to the method by Peacocke et al., ${ }^{24}$ and the results obtained for each system are shown in Figure 2, where the amount of bound AD per nulceotide phosphorus, $r$ is plotted against the molar ratio, $\mathrm{AD} / \mathrm{P}$ of $\mathrm{AD}$ to nucleotide phosphorus, $\mathrm{P}$. It is seen in Figure 2 that $r$ increases linearly at first, and then in the $A D / P$ region of about 0.15 to 0.20 , levels off with increasing $\mathrm{AD} / \mathrm{P}$. These results mean the termination of interaction between DNA and AD for intercalation in the $\mathrm{AD} / \mathrm{P}$ region of about 0.15 to 0.20 .

In addition, Scatchard's plots for each system are shown in Figure 3 to obtain binding parameters. From the plots, the binding parameters were estimated and are given in Table I. It is apparent that the binding parameters for 

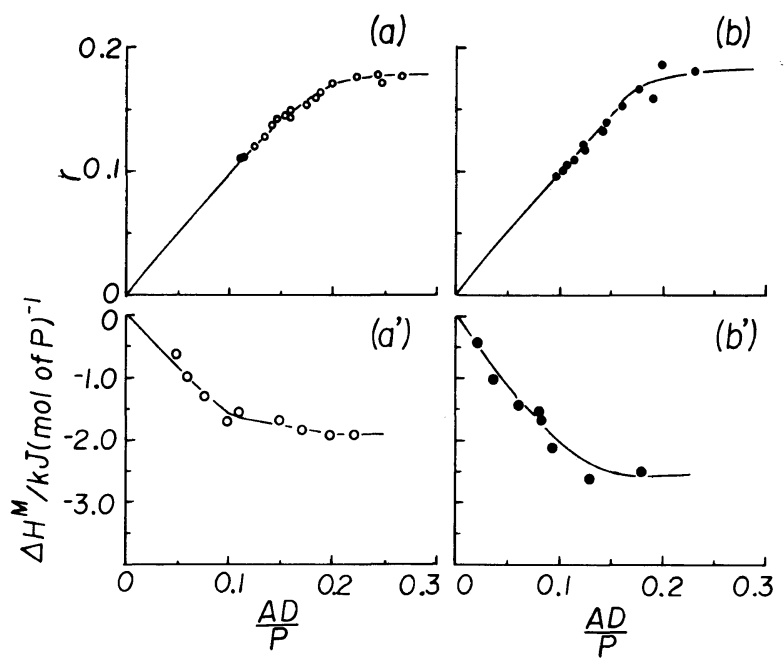

(b)
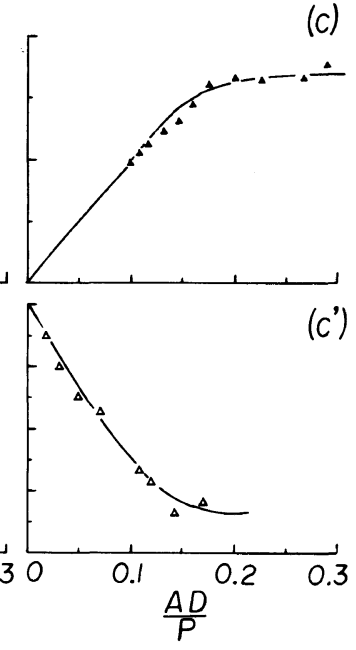

Figure 2. Dependence of the amount of bound adriamycin per mole of DNA phosphorus, $r$ and the heat of mixing per mole of DNA phosphorus, $\Delta H^{\mathrm{M}}$ on the molar ratio, $\mathrm{AD} / \mathrm{P}$ of adriamycin to DNA phosphorus. (a) and (a'), DNA (I) (GC content 26.5\%); (b) and (b'), DNA (II) (GC content 50\%); (c) and (c'), DNA (III) (GC content $72 \%$ ).

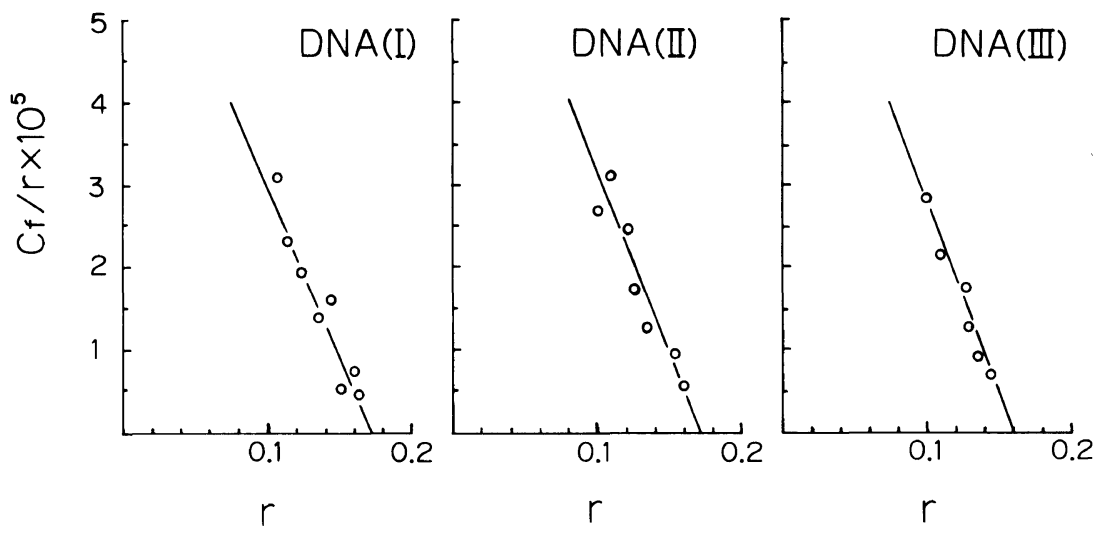

Figure 3. Scatchard plots for adriamycin solution of various GC content of DNA: DNA (I), $26.5 \%$; DNA (II), $50 \%$; DNA (III), $72 \%$.

Table I. The binding parameters for intercalation of DNA-adriamycin complex as estimated from spectrophotometry

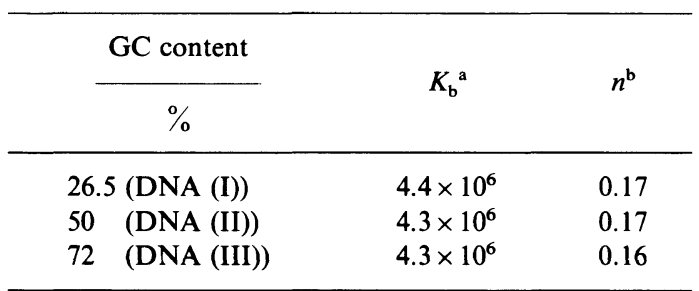

a Binding constant.

b Number of binding sites per DNA phosphorus. each system have similar values.

\section{Heat of Mixing for DNA and AD Solutions}

In order to estimate the enthalpy change of complex formation accompanying intercalation, the heats of mixing for each DNA-AD system were measured over the $\mathrm{AD}$ concentration range of $5 \times 10^{-5}$ to $1 \times 10^{-4} \mathrm{~mol}$ $\mathrm{dm}^{-3}$ at $298.15 \pm 0.005 \mathrm{~K}$. In this case, the DNA concentration was kept constant at $5.0 \times 10^{-4} \mathrm{~mol} \mathrm{dm}^{-3}$ in nucleotide phos- 
phorus.

All systems proved to be exothermic, indicating that the complex between DNA and $\mathrm{AD}$ was formed. The observed heats of mixing, $\Delta Q$ at different $\mathrm{AD}$ concentration, $C$ and molar ratio, $\mathrm{AD} / \mathrm{P}$ of $\mathrm{AD}$ to $\mathrm{DNA}$ phosphorus, $\mathrm{P}$ are listed in Table III. The results obtained are presented graphically in Figure 2, where the heat of mixing per mole of phosphorus of DNA, $\Delta H^{\mathrm{M}}$ is plotted against $\mathrm{AD} / \mathrm{P}$. As seen in Figure 2, the absolute value of $\Delta H^{\mathrm{M}}$ for each system increases at first, and then reaches a definite value at a high value of $\mathrm{AD} / \mathrm{P}$. This behavior of $\Delta H^{\mathrm{M}}$ against $\mathrm{AD} / \mathrm{P}$ is comparable with that of $r$ against $\mathrm{AD} / \mathrm{P}$ obtained from the spectral measurements in Figure 2. We suggest that $\Delta H^{\mathrm{M}}$ obtained is based on intercalation. In addition, the limiting value of $\Delta H^{\mathrm{M}}$ becomes more exothermic with increasing GC content, suggesting that the evaluated heat by mixing may reflect GC content dependence of the heat of interaction of AD with a base of DNA.

Furthermore, the observed heat of mixing $\Delta Q$ may contain the heat based on the dissociation of $\mathrm{AD}$ dimer to monomer because aromatic compounds such as dye (ethidium bromide, proflavine) or antibiotics (daunomycin, adriamycin) form the dimerization in water. By taking into account the heat of dissociation of $\mathrm{AD}$ dimer to monomer, we estimated the heat of interaction between DNA and AD monomer in the next section.

Thermodynamic Parameters for Binding of $A D$ to $D N A$

Assuming that the DNA-AD complex for mixture of DNA and AD is formed between DNA and monomeric $\mathrm{AD}$ and that the dimeric form of AD does not bind DNA, the reaction in the mixing solution of DNA and $\mathrm{AD}$ can be expressed as follows,

$$
(\mathrm{AD})_{2} \rightleftharpoons 2 \mathrm{AD}
$$

$\mathrm{AD}+\mathrm{DNA} \rightleftharpoons(\mathrm{DNA}-\mathrm{AD})$ complex with the dissociation constant $K_{\mathrm{d}}$ for AD dimer to monomer for reaction (1) and the binding constant $K_{\mathrm{b}}$ of DNA-AD complex formation for reaction (2). Before the mixing of DNA and AD solutions, we have

$$
K_{\mathrm{d}}=C_{\mathrm{fi}}^{2} / C_{2 \mathrm{i}} \text { and } C=C_{\mathrm{fi}}+2 C_{2 \mathrm{i}}
$$

where $C_{2 \mathrm{i}}$ and $C_{\mathrm{fi}}$ are the initial dimer and monomer concentration of $\mathrm{AD}$ without the DNA solution, and $C$ is the total concentration of AD. From eq 3, we have

$$
C_{2 \mathrm{i}}=\frac{1}{2}\left(\frac{K_{\mathrm{d}}}{4}+C-\sqrt{\left.\left(\frac{K_{\mathrm{d}}}{4}+C\right)^{2}-4 C^{2}\right)}\right.
$$

After equilibration of the mixture of DNA and AD solution, we have

$$
\begin{aligned}
& K_{\mathrm{d}}=\frac{C_{\mathrm{f}}^{2}}{C_{2}} \\
& K_{\mathrm{b}}=\frac{C_{\mathrm{b}}}{C_{\mathrm{f}}\left(n P-C_{\mathrm{b}}\right)} \\
& C=C_{\mathrm{f}}+C_{\mathrm{b}}+2 C_{2}
\end{aligned}
$$

where $C_{\mathrm{f}}, C_{2}$, and $C_{\mathrm{b}}$ are the concentrations of monomeric $\mathrm{AD}$, the dimeric $\mathrm{AD}$, and the bound $\mathrm{AD}$ in DNA-AD complex, respectively, and $C$ is the total concentration of $\mathrm{AD}$, $n$ the number of binding site per nucleotide phosphorus of DNA, and $P$ the concentration in nucleotide phosphorus of DNA, respectively. From eq 5 to 7 , we have

$$
\begin{aligned}
C_{\mathrm{f}}^{3}+ & \left(\frac{K_{\mathrm{d}}}{2}+\frac{1}{K_{\mathrm{b}}}\right) C_{\mathrm{f}}^{2}+\left(\frac{K_{\mathrm{d}}}{2} n P+\frac{K_{\mathrm{d}}}{2 K_{\mathrm{b}}}-\frac{K_{\mathrm{d}}}{2} C\right) \\
& \times C_{\mathrm{f}}-\frac{K_{\mathrm{d}}}{2 K_{\mathrm{b}}} C=0
\end{aligned}
$$

The observed heat $\Delta Q / V$ per volume of mixture obtained from the mixing of DNA and AD solutions is given by

$$
\frac{\Delta Q}{V}=C_{\mathrm{b}} \Delta H_{\mathrm{b}}+\left(C_{2 \mathrm{i}}-C_{2}\right) \Delta H_{\mathrm{d}}
$$

where $\Delta H_{\mathrm{b}}$ is the heat of binding of $\mathrm{AD}$ to DNA, $\Delta H_{\mathrm{d}}$ the heat of dissociation of $\mathrm{AD}$ dimer to monomer, respectively. 
Table II. Observed heat of mixing per volume of solution, $\Delta Q / V$, the heat of mixing, $\Delta H^{\mathrm{M}}$, and the heat of binding of adriamycin to DNA, $\Delta H_{\mathrm{b}}$ with concentration of adriamycin, $C$, and with molar ratio, $\mathrm{AD} / \mathrm{P}$

\begin{tabular}{|c|c|c|c|c|}
\hline$C \times 10^{5}$ & \multirow{2}{*}{$\mathrm{AD} / \mathrm{P}$} & \multirow{2}{*}{$\frac{-\Delta Q / V}{\mathrm{Jdm}^{-3}}$} & \multirow{2}{*}{$\frac{-\Delta H^{\mathrm{M} \mathrm{a}}}{\mathrm{kJ} \mathrm{mol}^{-1}}$} & \multirow{2}{*}{$\frac{-\Delta H_{\mathrm{b}}^{\mathrm{b}}}{\mathrm{kJ} \mathrm{mol}^{-1}}$} \\
\hline $\mathrm{mol} \mathrm{dm}^{-3}$ & & & & \\
\hline \multicolumn{5}{|c|}{ DNA (I) (GC content $26.5 \%$ ) system } \\
\hline 2.51 & 0.050 & 0.308 & 0.62 & 13.8 \\
\hline 3.04 & 0.062 & 0.528 & 1.06 & 18.9 \\
\hline 3.95 & 0.078 & 0.668 & 1.32 & 18.9 \\
\hline 4.97 & 0.099 & 0.861 & 1.71 & 19.6 \\
\hline 5.86 & 0.114 & 0.777 & 1.52 & 15.7 \\
\hline 7.44 & 0.149 & 0.834 & 1.67 & 14.0 \\
\hline 8.49 & 0.170 & 0.933 & 1.87 & 14.5 \\
\hline 9.92 & 0.197 & 0.956 & 1.90 & 14.8 \\
\hline 11.20 & 0.224 & 0.957 & 1.91 & 15.0 \\
\hline \multicolumn{5}{|c|}{ DNA (II) (GC content $50 \%$ ) system } \\
\hline 1.00 & 0.020 & 0.230 & 0.46 & 23.9 \\
\hline 1.94 & 0.038 & 0.527 & 1.04 & 28.5 \\
\hline 3.22 & 0.063 & 0.736 & 1.44 & 24.7 \\
\hline 3.96 & 0.079 & 0.785 & 1.57 & 21.9 \\
\hline 4.02 & 0.081 & 0.825 & 1.66 & 22.6 \\
\hline 4.85 & 0.097 & 1.101 & 2.19 & 25.0 \\
\hline 6.52 & 0.130 & 1.317 & 2.63 & 22.9 \\
\hline 9.04 & 0.183 & 1.237 & 2.48 & 17.9 \\
\hline \multicolumn{5}{|c|}{ DNA (III) (GC content $72 \%$ ) system } \\
\hline 0.99 & 0.020 & 0.236 & 0.47 & 24.6 \\
\hline 1.50 & 0.029 & 0.488 & 0.96 & 33.7 \\
\hline 2.52 & 0.051 & 0.750 & 1.52 & 31.4 \\
\hline 3.74 & 0.075 & 0.887 & 1.77 & 25.7 \\
\hline 5.58 & 0.111 & 1.349 & 2.69 & 26.7 \\
\hline 6.00 & 0.120 & 1.444 & 2.89 & 26.7 \\
\hline 7.14 & 0.143 & 1.714 & 3.44 & 27.1 \\
\hline 8.56 & 0.172 & 1.613 & 3.25 & 23.4 \\
\hline
\end{tabular}

${ }^{\text {a }}$ Heat per mole of DNA phosphorus.

b Heat per mole of adriamycin.

The solution of eq 8 was obtained by an interative procedure using a computer. According to eq 9 , we obtained $\Delta H_{\mathrm{b}}$ for a given $C$ using values of $K_{\mathrm{d}}(=1100$ at $298 \mathrm{~K})$ and $\Delta H_{\mathrm{d}} \quad\left(=40 \mathrm{~kJ} \mathrm{~mol}^{-1}\right)$ reported by Crescenzi and Quadrifoglio ${ }^{25}$ and $K_{\mathrm{b}}$ and $n$ values (Table II) obtained from Scatchard's plots. $\Delta H_{\mathrm{b}}$ obtained as a function of $\mathrm{AD}$ concentration for each system is summarized in the last column of Table II and shown in Figure 4. It is clear that $\Delta H_{\mathrm{b}}$ is independent of

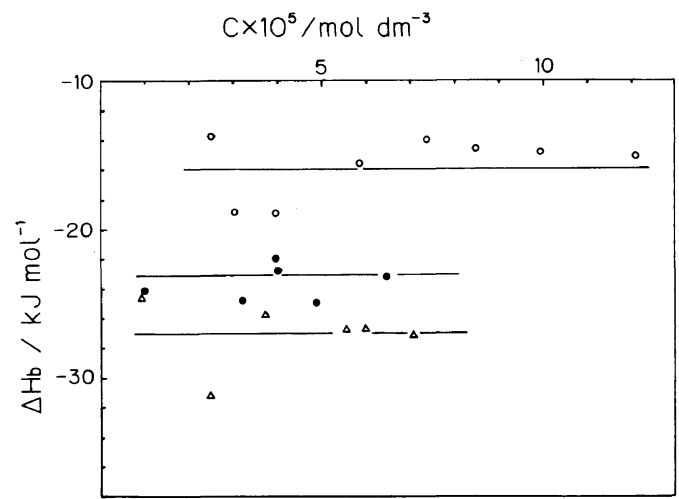

Figure 4. Enthalpy change of binding, $\Delta H_{\mathrm{b}}$ of adriamycin to various GC content of DNA corrected for dimerization of the adriamycin as function of adriamycin concentration. GC content of DNA: $\bigcirc, 26.5 \%$;

$50 \% ; \triangle, 72 \%$.

Table III. Thermodynamic parameters for adriamycin binding to DNA at $298 \mathrm{~K}^{\mathrm{a}}$

\begin{tabular}{|c|c|c|c|}
\hline GC content & $\Delta G_{\mathrm{b}}$ & $\Delta H_{\mathrm{b}}$ & $\Delta S_{\mathrm{b}}$ \\
\hline$\%$ & $\mathrm{~kJ} \mathrm{~mol}^{-1}$ & $\mathrm{~kJ} \mathrm{~mol}^{-1}$ & $\mathrm{~J} \mathrm{~K}^{-1} \mathrm{~mol}^{-1}$ \\
\hline DNA (I) 26.5 & -38 & -16 & 74 \\
\hline DNA (II) 50 & -38 & -23 & 50 \\
\hline DNA (III) 72 & -38 & -27 & 37 \\
\hline
\end{tabular}

a Mol here refers to moles of adriamycin.

AD concentration although the calculated values are scattered. The average value (solid line in Figure 4) of $\Delta H_{\mathrm{b}}$ obtained for each system is listed in Table III, together with values of the free energy change $\Delta G_{\mathrm{b}}$ and the entropy change $\Delta S_{\mathrm{b}}$ based on the intercalation process calculated from the equations, $\Delta G_{\mathrm{b}}=$ $-R T \ln K_{\mathrm{b}}$ and $\Delta S_{\mathrm{b}}=\left(\Delta H_{\mathrm{b}}-\Delta G_{\mathrm{b}}\right) / T$.

The thermodynamic parameters estimated for DNA-AD interaction are comparable with those for DNA-daunomycin interaction using calorimetry, ${ }^{26,27}$ but the DNA-daunomycin was characterized by negative entropy change from van't Hoff analysis. ${ }^{28}$ This discrepancy is based on differences in enthalpy change: The enthalpy change estimated from calorimetry is significantly less than that from van't Hoff analysis although the magnitude of free energy 
change has the same value. However, it is very difficult to assess this discrepancy between calorimetrical and van't Hoff methods for enthalpy change based on intercalation process.

As seen in Table III, AD intercalated into DNA exists as a stable complex from the negative value of $\Delta G_{\mathrm{b}}$ for each DNA-AD system. This stability of the complex is due to negative enthalpic and positive entropic contributions, although the formation of the complex is generally characterized by negative values for both enthalpy and entropy changes.

The entropic gain accompanying the interaction process seems to result from increase in the degree of disorder of water molecules in hydration shells surrounding the DNA-AD complex as in the reverse process of solubilization of hydrocarbons in water. ${ }^{29,30}$

Furthermore, it is of interest that the enthalpy change decreases with increasing GC content although the free energy change is independent of GC content, demonstrating that the mechnism of binding of $\mathrm{AD}$ into DNA depends on the base sequence of DNA molecules.

\section{Base Specificity for Intercalation}

Assuming that the three types of DNA-AD interaction (i.e., between GC pairs, AT pairs, and $\mathrm{GC}-\mathrm{AT}$ pairs) occur in the numbers given by the probability of existence of such pairs when the DNA molecule corresponds to a random base sequence, the enthalpy change of DNA-AD interaction is represented as,

$$
\Delta H_{\mathrm{b}}=\Delta H_{1} n_{\mathrm{GC}}^{2}+\Delta H_{2} n_{\mathrm{AT}}^{2}+2 \Delta H_{3} n_{\mathrm{GC}} n_{\mathrm{AT}}
$$

where $\Delta H_{1}, \Delta H_{2}$, and $\Delta H_{3}$ are the enthalpy changes between GC/GC base pairs and $\mathrm{AD}$, $\mathrm{AT} / \mathrm{AT}$ base pairs and AD, and GC/AT base pairs and $\mathrm{AD}$, respectively, and $n_{\mathrm{GC}}$ and $n_{\mathrm{AT}}$ are the fractions of GC and AT base pairs in DNA molecules, respectively.

Since $n_{\mathrm{AT}}$ is equal to $1-n_{\mathrm{GC}}, \Delta H_{\mathrm{b}}$ may be rewritten as a function of $n_{\mathrm{GC}}$,

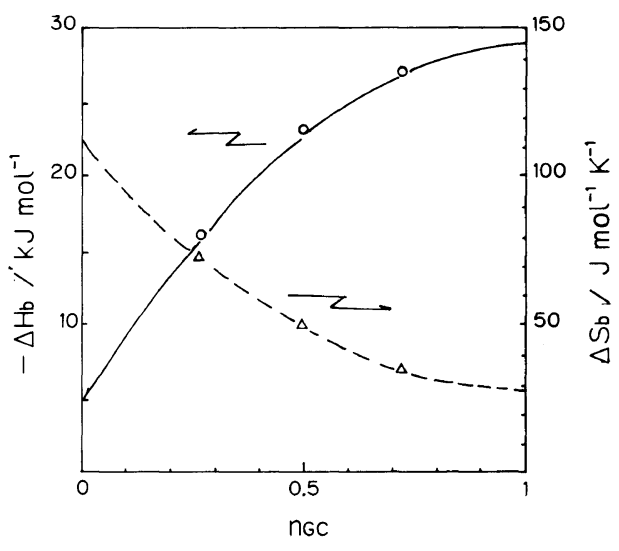

Figure 5. Dependence of the enthalpy change, $\Delta H_{\mathrm{b}}$ (O) and entropy change, $\Delta S_{\mathrm{b}}(\triangle)$ accompanying intercalation of adriamycin on GC content of DNA.

Table IV. Thermodynamic parameters for the intercalation process of adriamycin into base composition of DNA $^{\mathrm{a}}$

\begin{tabular}{|c|c|c|c|}
\hline \multirow{2}{*}{$\begin{array}{l}\text { Base pair } \\
\text { sequence }\end{array}$} & $\Delta H_{i}$ & $\Delta S_{i}$ & $\Delta G_{i}$ \\
\hline & $\mathrm{kJ} \mathrm{mol}^{-1}$ & $\mathrm{~J} \mathrm{~K}^{-1} \mathrm{~mol}^{-1}$ & $\mathrm{~kJ} \mathrm{~mol}^{-1}$ \\
\hline $\mathrm{GC} / \mathrm{GC}$ & -29 & 29 & -38 \\
\hline $\mathrm{GC} / \mathrm{AT}$ & -29 & 28 & -37 \\
\hline $\mathbf{A T} / \mathbf{A T}$ & -5 & 111 & -38 \\
\hline
\end{tabular}

a $i$ is number $(1,2$, and 3$)$ in text

Mol refers to moles of adriamycin.

$$
\begin{aligned}
& \Delta H_{\mathrm{b}}=\left(\Delta H_{1}+\Delta H_{2}-2 \Delta H_{3}\right) n_{\mathrm{GC}}^{2} \\
& +2\left(\Delta H_{3}-\Delta H_{2}\right) n_{\mathrm{GC}}+\Delta H_{2}
\end{aligned}
$$

The plots of $\Delta H_{\mathrm{b}}$ estimated from calorimetry versus GC fraction of DNA are shown in Figure 5, and the solid line in Figure 5 shows the best fit curve of eq 11 by least squares treatment. Each heat of interaction, $\Delta H_{i}(i=1$, 2 , and 3 ) as estimated from this curve is shown in Table IV.

The entropy change $\Delta S_{i}$ for the intercalation process was estimated in essentially the same way as that of $\Delta H_{i}$ as mentioned above. The results obtained are also summarized in Table IV, together with values of the free energy change, $\Delta G_{i}$ calculated by $\Delta G_{i}=\Delta H_{i}-T \Delta S_{i}$ at $298 \mathrm{~K}$. 
As seen in Table IV, the thermodynamic parameters for $\mathrm{AD}$ intercalated between GC/GC base pairs and between GC/AT base pairs have similar values, but the enthalpy change for $\mathrm{AD}$ intercalated between $\mathrm{AT} / \mathrm{AT}$ base pairs is considerably larger than that between GC/GC base pairs although the free energy change has similar value. From these facts, we suggest that the interaction mode between GC base pair and AD is different from that between AT base pair and AD.

\section{CONCLUSIONS}

The thermodynamic parameters of the intercalation process for DNA-adriamycin interaction were estimated from calorimetry, taking into account the self association of the AD molecule. The intercalated AD into DNA was due to both enthalpic and entropic contributions. The entropic gain accompanying intercalation seems to result from increase in the degree of disorder of the hydration shell surrounding the DNA-AD complex compared with the hydration of DNA and AD. In addition, the interaction energy of base with AD is larger for GC than AT base pairs although the free energy change for the intercalated AD between base pairs is independent of the base composition of DNA.

\section{REFERENCES}

1. A. Blake and A. R. Peacocke, Biopolymers, 6, 1225 (1968).

2. M. J. Waring, Ann. Rev. Biochem., 50, 159 (1981).

3. W. Muller and D. M. Crothers, J. Mol. Biol., 35, 251 (1968).

4. L. V. Crawford and M. J. Waring, J. Mol. Biol., 25, 23 (1967).

5. L. S. Lerman, J. Mol. Biol., 3, 18 (1961).

6. P. J. Bond, R. Langridge, K. W. Jennette, and S. J. Lippard, Proc. Natl. Acad. Sci., U.S.A., 72, 4825 (1972).

7. G. Cohen and H. Eisenberg, Biopolymers, 8, 45 (1969).
8. T. D. Sakore, S. C. Jain, C. C. Tsai, and H. M. Sobell, Proc. Natl. Acad. Sci., U.S.A., 74, 188 (1977).

9. S. Neidel, A. Achari, G. L. Taylor, H. M. Berman, H. L. Carrell, J. P. Glusker, and W. C. Stallings, Nature, 269, 304 (1977).

10. K. Kanoh, Y. Baba, and A. Kagemoto, Polym. J., 15, 657 (1983).

11. S. Tanaka, Y. Baba, and A. Kagemoto, Makromol. Chem., 182, 2837 (1981).

12. K. Kanoh, Y. Baba, and A. Kagemoto, Thermochimica Acta, 88, 323 (1985).

13. W. J. Pigran, W. Fuller, and L. D. Hamilton, Nature, 235, 17 (1972).

14. E. Calendi, A. Dimarco, M. Reggiani, B. Scarpinato, and L. Valentini, Biochem. Biophys. Acta, 103, 25 (1965).

15. W. Kersten, H. Kersten, and E. Szybalski, Biochemistry, 5, 236 (1966).

16. G. L. Quigley, A. H. Wang, G. Ughetto, G. van der Marel, J. H. van Boom, and A. Rich, Proc. Natl. Acad. Sci., U.S.A., 77, 7204 (1980).

17. R. Langridge, D. A. Marvin, W. E. Seeds, H. R. Wilson, C. W. Hooper, M. H. F. Wilkins, and L. D. Hamilton, J. Mol. Biol., 2, 38 (1960).

18. S. Arnott, D. W. L. Hukins, S. D. Dover, W. Fuller, and A. R. Nodgson, J. Mol. Biol., 81, 107 (1973).

19. Y. Baba, S. Tanaka, and A. Kagemoto, Makromol. Chem., 178, 2111 (1977).

20. P. S. Chen, T. Y. Toribaya, and H. Warner, Anal. Chem., 28, 1756 (1956).

21. R. W. Armstrong, T. Kurkucsev, and U. P. Strauss, J. Am. Chem. Soc., 92, 3174 (1970).

22. D. O. Jordon and L. N. Sanson, Biopolymers, 10, 399 (1971).

23. S. Tanaka, Y. Baba, and A. Kagemoto, Makromol. Chem., 182, 1475 (1981).

24. A. R. Peacocke and J. N. H. Skerrett, Trans. Faraday Soc., 52, 261 (1956).

25. V. Crescenzi and F. Quadrifoglio, "Polyelectrolytes and Their Applications," Vol. 2, A. Rembaum and E. Selegry, Ed., D. Reidel Publishing Company, 1975, pp 217-230.

26. Y. M. Yaung and D. R. Phillips, Biophys. Chem., 6, 363 (1977).

27. F. Q. Quadrifoglio and V. Crescenzi, Biophys. Chem., 3, 64 (1974).

28. J. B. Chaires, Biopolymers, 24, 403 (1985).

29. H. S. Frank and M. W. Evans, J. Chem. Phys., 13, 505 (1985).

30. F. Franks, "Water a Comprehensive Treaties," F. Franks, Ed., Plenum Press, New York, N. Y., 1975, pp 1-94. 